\title{
Iberian thermal lows in a changed climate
}

\author{
Klaus P. Hoinka, ${ }^{a} *$ Miguel Gaertner ${ }^{\mathrm{b}}$ and Manuel de Castro ${ }^{\mathrm{b}}$ \\ ${ }^{a}$ Institut für Physik der Atmosphäre, DLR, Oberpfaffenhofen, Germany \\ b Dpto. Ciencias Ambientales, Universidad Castilla-La Mancha, Toledo, Spain
}

\begin{abstract}
Recent results from enhanced greenhouse-gas scenarios over southern Europe suggest that climate change implies a summertime mean surface warming of up to $4 \mathrm{~K}$ over the Iberian Peninsula. It is suggested that thermal lows, the most prominent Iberian summer weather, will undergo significant modifications in a changed climate. This is studied in the present paper by determining statistical features of the Iberian thermal low, at first for today's climate using data provided by ERA-40 and by the regional climate model PROMES. In general the analysed and simulated climatic structures compare well. However, the ERA-40 data provide conditions more favourable for thermal lows than simulated with the model. Statistics in a changed climate are obtained by performing two 30-year model simulations for 1961-1990 and 2071-2100. It is found that thermal lows strengthen by decreasing the central Iberian surface pressure from 1012.2 to $1010.5 \mathrm{hPa}$ and increasing its daily variation by about $7 \%$ in magnitude. Associated with this is an increase in the number of thermal low days by more than $60 \%$. A second finding is an enhancement of the sea breezes over the Iberian westerly and easterly coasts and a particularly significant strengthening of the sea breeze between Cadiz and Huelva. The westerly flow over the Strait of Gibraltar, observed during thermal low events, decreases. The increase in occurrence of the thermal low is associated with a significant increase in the number of dry spells of longer period, and could involve considerable impact on desertification, water resources and wildfire hazards around the Mediterranean basin. The results suggest that there is some evidence that the subtropical character of the Mediterranean climate strengthens. Copyright (C) 2007 Royal Meteorological Society
\end{abstract}

KEY WORDS climate change; Iberian peninsula; ERA-40 data; thermal low

Received 26 June 2006; Revised 13 February 2007; Accepted 28 February 2007

\section{Introduction}

Thermal lows occur frequently over the Iberian Peninsula (henceforth denoted by IP) during summer and are thought to be the most prominent example of this phenomenon in Europe. Thermal lows represent, with about $14 \%$ annual percentage of occurrence, an important part of all possible IP weather types. During summer the thermal low frequency increases to about $42 \%$ and becomes the dominant weather type (Hoinka and Castro, 2003; henceforth HC03). The IP centre's summer is very dry with an average summer rainfall of about 5-20 mm together with a daily potential evapotranspiration amounting e.g. to $\sim 4 \mathrm{~mm} \mathrm{day}^{-1}$ for Madrid (Linés, 1970). This indicates the sensitive hydrological balance at present in the semi-arid summertime IP. Under climatic change, this balance could be dramatically disturbed. In the past this region has already experienced a weak climate change. For the period 1891 to 1990 , Schönwiese et al. (1994) determined a summer temperature increase of $0.5 \mathrm{~K}$; for the same period the summer precipitation decreased by about $10 \mathrm{~mm}$, but the annual precipitation increased by

\footnotetext{
* Correspondence to: Klaus P. Hoinka, Institut für Physik der Atmosphäre, DLR, Postfach 1116, D-82230 Wessling, Germany.

E-mail: Klaus.Hoinka@dlr.de
}

$50 \mathrm{~mm}$ over northern Spain and decreased by $100 \mathrm{~mm}$ over southern Spain.

Future climatic change effects on European regions were determined in a systematic effort in the PRUDENCE project (Christensen et al., 2002), where various regional climate models (RCMs) were applied. The climate change scenario A2 is based on a transient greenhouse-gas scenario with an annual increase up to $850 \mathrm{ppm}$ in carbon dioxide until 2100 , as specified by the Intergovernmental Panel on Climate Change (IPCC, 2000). In scenario A2, most models forecast a summer temperature increase of 5-7 K (in the central IP) and $4-5 \mathrm{~K}$ (around the periphery of the IP) as well as a weaker one of $2-3 \mathrm{~K}$ in winter (IP in general). These ranges are comparable to those obtained from generalcirculation models (GCMs) for the entire Mediterranean basin (IPCC, 2001).

There is some additional evidence that in Europe the length of the meteorological seasons will change such that summer will be extended whereas winter will be shortened (Fronzek and Carter, 2007). The summer increase in temperature is associated with a significant decrease in evapotranspiration of up to $20 \%$ for most of the IP, with in some areas a decrease by more than $40 \%$. The societal consequences of increasing temperature and decreasing evapotranspiration would be extended 
droughts, increased threat of water scarcity and in turn a stronger hazard of wildfires, all favoured by long dry hot periods.

Therefore, in the present paper the climatology of thermal lows is investigated in a changing climate due to an increase of carbon dioxide. This is done by applying the RCM version of the mesoscale model PROMES (Castro et al., 1993) which contributed to the PRUDENCE project. Data of a control (CL) run (1961-1990) and scenario A2 simulations (2071-2100) are used to determine statistical features of the Iberian thermal low in a changing climate. The difference between $\mathrm{CL}$ and $\mathrm{A} 2$ will give indications of the atmosphere's modifications. However, one might question the model's ability to describe the present-day climate. The ability of the PROMES model to simulate the 1961-1990 mean climate and interannual variability has been analyzed together with the other RCMs involved in the PRUDENCE project, showing a good agreement with the seasonal surface temperature and precipitation climatology in the IP (Jacob et al., 2007).

In this study we compare the model-generated control climate with today's climatology of thermal lows over the IP based on the 44-year re-analysis (ERA-40) undertaken by the European Centre for Medium-range Weather Forecasts (ECMWF). For this comparison the climatology determined by $\mathrm{HC} 03$, based on a 15-year re-analysis (ERA-15; Gibson et al., 1997), is also considered. The comparison might help to provide sufficient knowledge of the present-day climatic state, being a necessary prerequisite for detecting a possible climatic change. This change is characterized by the statistics determined for the climate scenario A2.

The paper discusses data and criteria (Section 2), thermal low statistics in today's climate (Section 3), and those in a changed climate (Section 4).

\section{Data and criteria}

The European research initiative PRUDENCE (Christensen et al., 2002) involves three categories of numerical models: the low-resolution HadCM3 global atmosphere-ocean GCM, the intermediate-resolution HadAM3H atmospheric GCM, and ten limited-area highresolution RCMs. The HadCM3 simulation is a long integration using the observed atmospheric composition for 1859-1990 and scenario conditions for 1991-2100. For the HadAM3H and for the RCM simulation, two time-slice experiments are available, representing CL (1961-1990) and scenario A2 (2071-2100) conditions. All RCMs were driven at their lateral boundaries by the HadAM3H (Jacob et al., 2007).

In the present study, the RCM version of the hydrostatic and fully compressible primitive-equation model PROMES is applied (Castro et al., 1993). Vertical coordinates are pressure-based sigma, and a Lambert conformal projection is used in the horizontal, centred on $45^{\circ} \mathrm{N}, 6^{\circ} \mathrm{E}$, using an Arakawa-C grid. The horizontal grid resolution is $50 \mathrm{~km}$. A split-explicit integration scheme based on Gadd (1978) is used. Radiation is considered from Anthes et al. (1987) for absorption and scattering of short-wave radiation by clouds. Turbulent vertical exchange in the planetary boundary layer are modelled as proposed by Zhang and Anthes (1982). Soil-vegetation atmosphere exchanges are parametrized using the land-surface scheme SECHIBA (Ducoudré et al., 1993). Gaertner et al. (2001) provide further details. First PROMES results on the hydrological cycle changes due to deforestation are given in Gaertner et al. (2001). In the following, CL and A2 are used to denote the corresponding RCM simulation.

The present atmosphere's climate is considered to be best represented by time series of re-analysis data, such as the ERA-40 data (1958 to 2001) provided by ECMWF (Uppala et al., 2006). The statistics obtained with ERA40 data are compared with those determined recently from ERA-15 data for the period 1979-1993 (HC03). The analysis scheme applied in the ERA-40 project is based on the T157 spectral truncation, which corresponds to a resolution of about $1.125^{\circ}$ in latitude/longitude. (ERA-15 used T106.) For the present study, the data were interpolated to a finer grid resolution of $0.5^{\circ}$.

To decide if there is a heat low above the IP, the mean sea level pressure (mslp) at 06 and 18 UTC and the structure of the $925 \mathrm{hPa}$ surface are considered. Data from the $925 \mathrm{hPa}$ level are preferably used because the IP's mean surface height is at about the same level. Thus the analyzed data provide a better representation of observations than extrapolated mslp data. Additionally, Mohr (2004) pointed out that low-level geopotential fields are in hydrostatic balance during winter but out of hydrostatic balance during summer. Thus, the determination of the location of the summer thermal low's centre depends strongly on the extrapolation scheme used for evaluating the mslp. Following $\mathrm{HC} 03$, at the peak time of the heat low (18 UTC), height differences in the $925 \mathrm{hPa}$ surface between locations in peripheral and interior regions of the IP are determined along the coastal boundaries of the IP (see criterion (v) in the Appendix). The differences are labelled according to their location, e.g. (v) $)_{S W}$ for the height difference above the south-western IP. Additionally, the minimum height of the $925 \mathrm{hPa}$ suface must be located above the IP (criterion (iii)). $\mathrm{HC} 03$ gives a detailed description of the criteria. In the present study, these criteria are applied to the ERA-40 and RCM data to determine objectively the occurrence of Iberian heat lows.

\section{Thermal lows in the present climate}

In this section we discuss first the IP's summer climate and then the thermal low's climatology obtained from RCM data and compare it with those determined from ERA-40 and ERA-15 (HC03). Table I compares climate statistics of the occurrence of the IP's thermal low. 
Table I. Number of Iberian thermal low days based on ERA and RCM data.

\begin{tabular}{lcccc}
\hline Data period & ERA-15 & ERA-40 & RCM-CL & RCM-A2 \\
& $1979-1993$ & $1958-2001$ & $1961-1990$ & $2071-2100$ \\
\hline March & 0.9 & 1.0 & 0.4 & 0.6 \\
April & 1.0 & 2.7 & 1.0 & 1.3 \\
May & 4.3 & 7.0 & 2.6 & 4.9 \\
June & 10.1 & 14.5 & 6.1 & 9.9 \\
July & 14.1 & 20.2 & 9.9 & 13.9 \\
August & 14.0 & 18.1 & 7.1 & 6.2 \\
September & 5.4 & 8.3 & 2.8 & 1.0 \\
October & 0.7 & 1.5 & 0.6 & 6.8 \\
Spring & 6.2 & 10.7 & 4.0 & 35.6 \\
Summer & 38.2 & 52.8 & 23.1 & 7.2 \\
Autumn & 6.2 & 9.8 & 3.4 & 49.6 \\
Year & 50.6 & 73.3 & 30.5 & 36 \\
Min. annual number & 46 & 47 & 13 & 72 \\
Max. annual number & 56 & 108 & 47 & 9.0 \\
S.D. about the annual average & 3.0 & 15.1 & 8.5 & \\
\hline
\end{tabular}

(a)

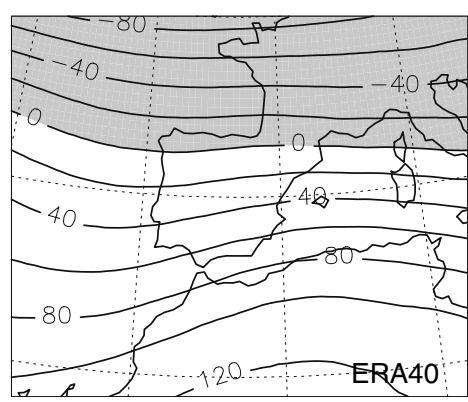

(b)

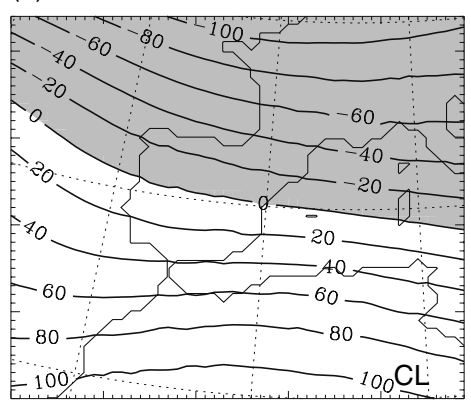

(c)

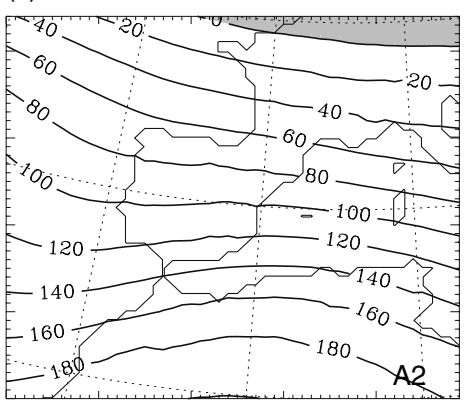

Figure 1. Summer average (JJA) of the 12 UTC $500 \mathrm{hPa}$ surface height (m reduced by $5800 \mathrm{~m}$ ): (a) ERA-40, (b) control run data CL, and (c) climate simulation A2. The increments are $20 \mathrm{~m}$ and the shaded areas mark regions with negative values.

\subsection{Iberian summer climate}

Figure 1 depicts the summer averages (June-August; JJA) of the mean height of the $500 \mathrm{hPa}$ surface (12 UTC) as obtained from ERA-40, from the CL, and from the A2 simulation. The characteristics of the A2 surface will be discussed in Section 4. The zero line $(=5800 \mathrm{~m})$ in the model-derived $500 \mathrm{hPa} \mathrm{JJA}$ averages for the $\mathrm{CL}$ is shifted southwards and has a slight north-west orientation compared with ERA-40. The comparison between ERA40 and $\mathrm{CL}$ indicates that the model simulates a more intense subtropical climate than is obtained from ERA40.

One reason for the resulting RCM structure is seen in the driving Hadley Centre Climate Model (HadAM3H) whose summertime average conditions show a less pronounced Iberian thermal low. This suggests that, if the RCM model had been driven by the ERA-40 data, a more pronounced averaged thermal low structure would have resulted. A comparison of the summer climates (JJA) from ERA-40 and HadAM3H suggests that the RCM model driven by the latter shifts the HadAM3H climate (not shown) toward the ERA-40 climate. The results indicate that the mid-tropospheric structure of the model data compares quite well with that determined from the ERA40 data. However, the lower the atmospheric level, the stronger is the role played by low-level influences such as orography, and a direct grid point to grid point comparison fails. Nevertheless, the general structure compares reasonably well. The climate resulting from ERA-40 data is considered to represent today's climate whereas the climate as determined with the RCM model characterizes the model climate, which is to a certain extent comparable to the present-day climate of ERA-40. The model climate is considered as a control state necessary for evaluating possible climate changes by model simulations. In that respect we consider the model climate as a quasi-realistic present-day reference state.

\subsection{Monthly frequency}

Applying all given criteria (see Section 2), the ERA15 and ERA-40 data reveal a different climatology of thermal low days. The ERA-15 data sample shows a July average of about 14 days with a thermal low, whereas this number increases to about 20 days in the ERA-40 data. If one considers only the 15 -year ERA-15 period 
from the ERA-40 sample, the monthly number of days remains almost unchanged. This is also valid for the period considered by the RCM (1961-1990).

One reason for the increase between ERA-15 and ERA-40 climatology is that the ERA-40's modified truncation allows a better resolution of low-tropospheric horizontal surfaces. This in turn forces a deepening of the summer average 18 UTC surface depression (not shown). This also increases the number of cases where the height minimum above the continental IP area is located above the central area. Due to the lower truncation of ERA15 data, the south-western and south-eastern regions of the IP show weaker inland gradients than for the ERA40 data. Thus an application of the criterion which uses $925 \mathrm{hPa}$ inland gradients excludes a good portion of thermal low days which appear as thermal low days in the ERA-40 dataset.

This was corroborated by various tests. As an illustrative example of this, if criteria (iii), (v) $)_{\mathrm{SE}}$ and (v) $)_{\mathrm{SW}}$ were excluded, the average number of days selected per year in ERA-40 is only $12 \%$ more than in ERA-15. But excluding only $(\mathrm{v})_{\mathrm{SE}}$ this percentage rises to $46 \%$, a value close to the difference of $48 \%$ between ERA-15 and ERA-40 when all the criteria are considered, as given in Table I. Based on a series of nine years of surface measurements, Portela and Castro (1991) have shown that the summer frequency of thermal low days clearly exceeds the $50 \%$ level. This is similar to the summer frequency as determined by the ERA- 40 data. All this suggests that the ERA-40 statistics are a good approximation to the present-day climate, and at least better than results from the ERA-15 data.

However, the application of the same criteria to the PROMES model yields a frequency of thermal lows that is clearly below that obtained for ERA-40 data. The criteria (see Appendix) were developed by $\mathrm{HC} 03$ in order to determine the Iberian thermal low based on ERA-15 data. There seems to be a strong sensitivity of these criteria to the data used, because the frequencies determined for ERA-40 become apparently greater than for the ERA-15 data. This is at least a hint that the scheme of criteria is not very robust in working independently of the kind of data used although, as mentioned above, there are various reasons for an increase in frequency from ERA-15 to ERA-40. It seems that the scheme is particularly useful for coarsely gridded data, such as those of ERA-15 and ERA-40, whereas its use is limited for smaller-scale gridded data such as those provided by the PROMES model.

As mentioned above, the control state and scenario A2 are simulated by the RCM (PROMES) which is nested in an atmospheric GCM. This control state time series corresponds to the present climate but not to the day-byday time series of observations. One has to keep in mind that the RCM results strongly depend on the GCM within which the RCM is nested (Räisänen et al., 2004)

Nevertheless, the relative monthly variation during the year shows an apparently similar pattern for all given periods as well as for all datasets. This suggests that the phase is correctly determined whereas the absolute amplitude is not. Despite the fact that the scheme of criteria seems to have deficiencies in capturing the absolute frequencies, one has to keep in mind that the present study deals with the change of frequencies from a control state to a modified climatic state. In this case the absolute amounts are of minor importance whereas the relative change is the key issue which contains the important information. This relative change will be determined by comparing the CL with the A2 state, both from PROMES, and can then be applied to today's observed state based on ERA-40. In that respect, it is reasonable to apply the same scheme of criteria for both data series, ERA as well as PROMES, even if the scheme seems not to be the best possible way of determining thermal lows for the latter dataset.

\subsection{Daily evolution}

In $\mathrm{HC} 03$ the average daily evolution of the mslp for July is given based on ERA-15 data (their Figure 6) which shows about the same structure as the mslp resulting from ERA-40 data (not shown here). Here we show the summer average of the height of the $925 \mathrm{hPa}$ surface (Figure 2, left column).

An interesting detail occurs over the southern IP. The daily evolution of the $925 \mathrm{hPa}$ surface shows that at 00 UTC the surface is above $800 \mathrm{~m}$, at 06 UTC it drops below, at 12 UTC it is lifted above, and finally at 18 UTC it again drops beneath the $800 \mathrm{~m}$ surface. This means that twice a day (00 and 12 UTC), there exists a bridge of lower $925 \mathrm{hPa}$ geopotential connecting the IP's thermal low with the Saharan one. To the west of the IP, a similar semi-diurnal oscillation is apparent in the $925 \mathrm{hPa}$ height. It is well known that in the surface pressure field there exists a semi-diurnal oscillation over much of the globe which is regularly distributed in its amplitude and phase (Haurwitz, 1956). The amplitude has its maximum in the Tropics and decreases polewards.

The semi-diurnal cycle can be easily seen in Figure 2 (left column). However, the amplitude and temporal phase of the observed tide are difficult to determine because of their global variety. Observations, re-analysis data and numerical simulations with GCMs show different magnitudes of the amplitude. The few earlier attempts to document tidal fluctuations in gridded data include work by Hsu and Hoskins (1989) which suggests that tidal fluctuations in the troposphere are reasonably well preserved in the ECMWF model. The semi-diurnal fluctuations in ECMWF data are consistent with the predictions of tidal theory based on the thermal forcing of stratospheric ozone and tropospheric water vapour. Based on global surface pressure data, Dai and Wang (1999) determined a maximum in the semi-diurnal amplitude between 1.0 and $1.3 \mathrm{hPa}$; re-analyses by the US National Center for Atmospheric Research/National Centers for Environmental Prediction obtained a peak amplitude of $1.47 \mathrm{hPa}$ (van den Dool et al., 1997). Re-analysis data appear to have stronger tides than has been reported classically 

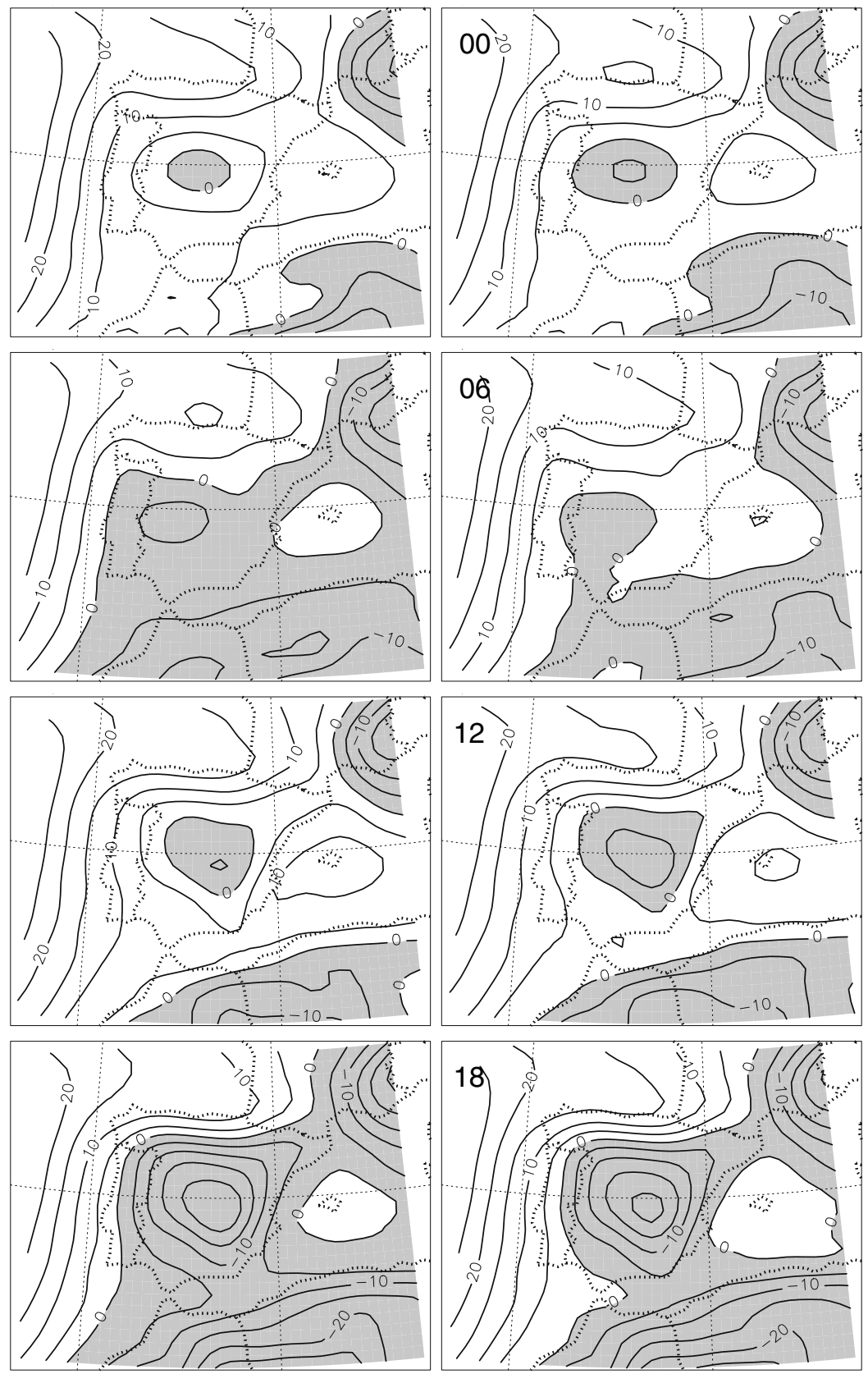

Figure 2. Diurnal evolution of the summer (JJA) average height of the $925 \mathrm{hPa}$ surface (m, reduced by $800 \mathrm{~m}$ ) between 00 and $18 \mathrm{UTC}$ for thermal lows based on ERA-40 data. The left column shows the original data, and the right column depicts the data after the removal of the semi-diurnal pressure signal. The shaded areas indicate regions with negative values.

from hourly surface station data. Here we apply a peak amplitude of $1.34 \mathrm{hPa}$ for the ERA-40 data (Hoinka, 2007) which is about $13.4 \mathrm{~m}$ for the $925 \mathrm{hPa}$ height.

Figure 2 (right column) shows the daily evolution of the isolated thermal low signal where the semi-diurnal pressure wave is removed. The filtered pressure field clearly exhibits the diurnal thermal cycle. In contrast to this, the left column depicts the observed total pressure distribution. The daily range in pressure height is the same for both sets of data.

The three-hourly resolution of CL (Figure 3) indicates a peak hour around 18 UTC, but it could be somewhere between 15 and 18 UTC, possibly closer to the later time, as has been pointed out by Portela and Castro (1991).
The daily amplitude between 12 and 18 UTC reaches up to $40 \mathrm{~m}$ in the IP's centre which is greater than the amplitude analysed with ERA-40 data. During its peak hours, the Iberian thermal low is clearly separated from its Saharan counterpart which is also found from the ERA-40 data. The Iberian thermal low disappears during the night whereas the Saharan one weakens slightly but remains. Figure 3 also shows a daily variation of disturbances above the Pyrenees and the Alps. These disturbances vanish during the day and between 15 and 18 UTC there seems to occur a weak thermal low above the Alps.

In the daily evolution of the RCM data (Figure 4) the semi-diurnal pressure wave also exists, however the 

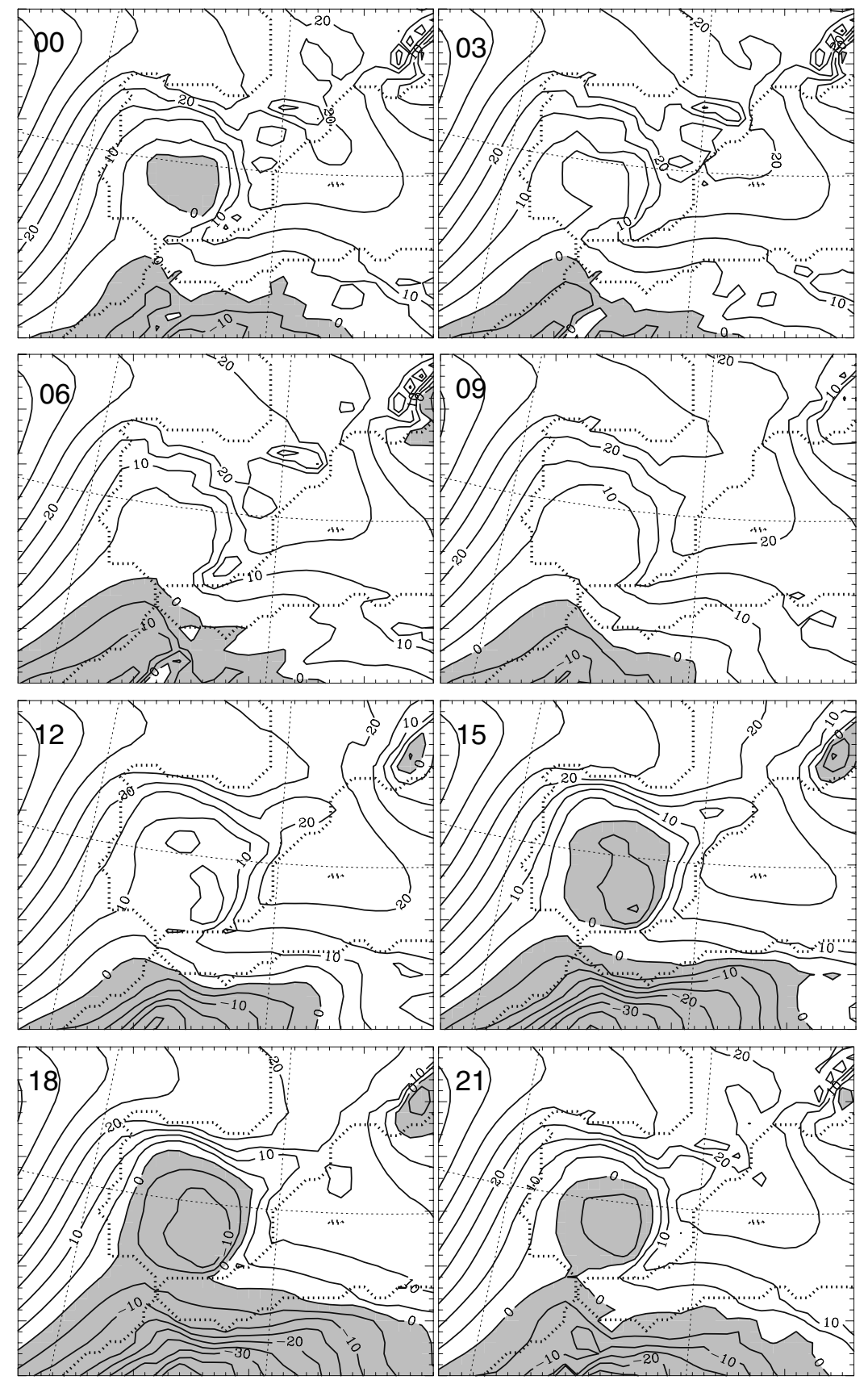

Figure 3. Diurnal evolution of the summer (JJA) average height of the $925 \mathrm{hPa}$ surface (m, reduced by $800 \mathrm{~m}$ ) between 00 and 21 UTC for thermal lows for CL based on RCM data. The shaded areas indicate regions with negative values.

signal is less strong (range $\approx 20 \mathrm{~m}$ ) than analyzed for the ERA-40 data $(\approx 25 \mathrm{~m}$; Figure 2$)$. Calculations with RCM data indicate that on thermal low days the daily amplitude of the central Iberian pressure remains unchanged after the removal of the semi-diurnal pressure signal. However, the isolated thermal low pressure signal indicates that the peak time is shifted toward 21 UTC, as can be seen in Figure 4 (left column). The 18 and 21 UTC panels of this figure should be compared with the corresponding panels of Figure 3. Nevertheless, in the following we will restrict ourselves to the discussion of the original RCM data because the daily pressure amplitude remains unchanged.

\subsection{Surface flow}

The shallow thermally forced depression causes radial inflow into the low's centre producing flow convergence and in turn an ascending motion which can amount to several $\mathrm{cm} \mathrm{s}^{-1}$ in the climatological average, as shown by $\mathrm{HC} 03$. This circulation produces a mass exchange between the heat low's centre and its surrounding environment. Figure 5 depicts the daily evolution of the surface flow simulated for CL. Only four times are given because the evolution develops gradually. The maximum velocities are around $10 \mathrm{~m} \mathrm{~s}^{-1}$. Panels for 00 and 06 UTC show a flow parallel to the coast from the north over Portugal. Later in the day, an inland flow strengthens, 

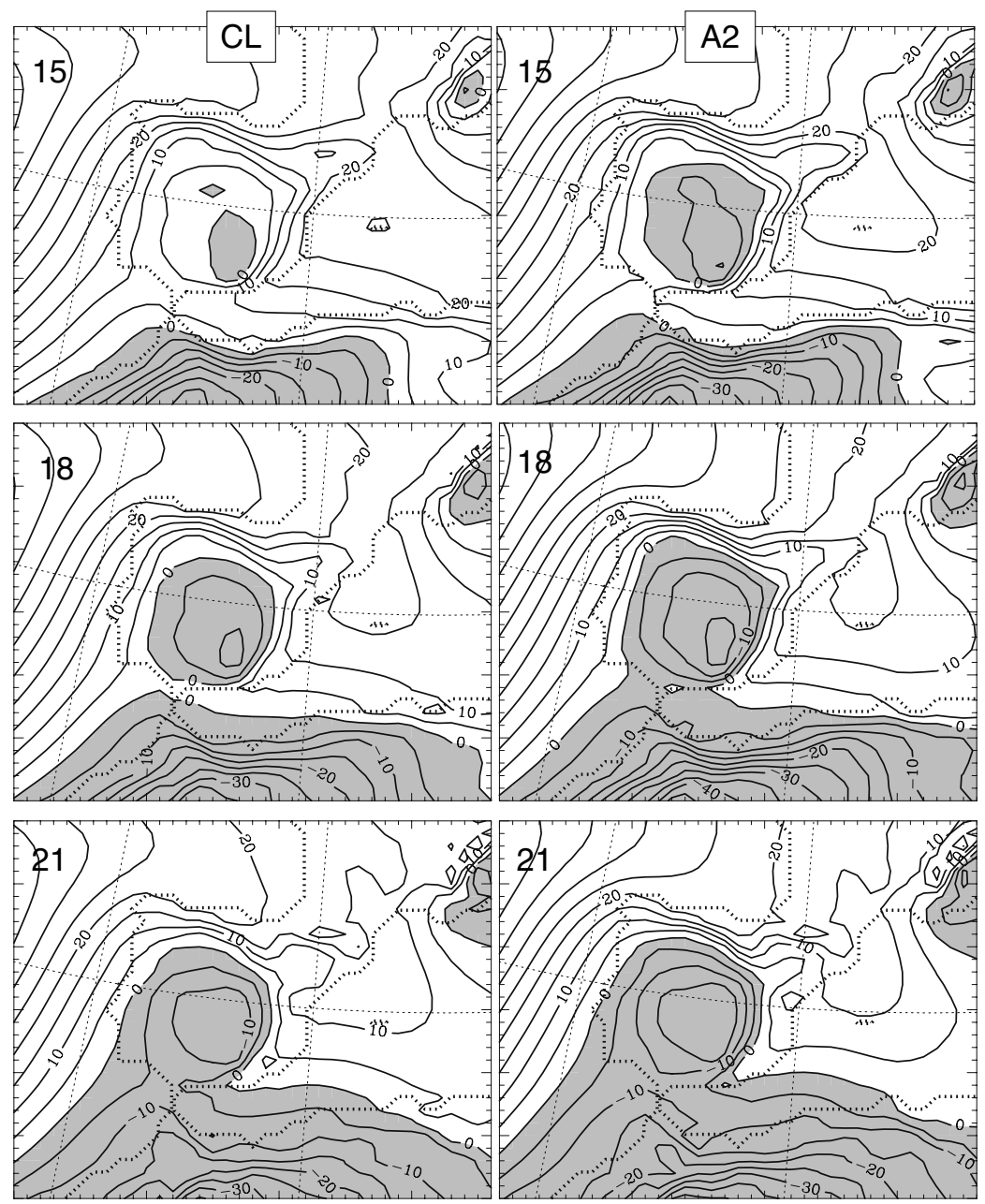

Figure 4. Diurnal evolution of the summer (JJA) average height of the $925 \mathrm{hPa}$ surface (m, reduced by $800 \mathrm{~m}$ ) between 15 and 21 UTC for thermal lows based on RCM data (CL and A2) - the structure after the removal of the semi-diurnal pressure signal. The left column should be compared with Figure 3, the right column with Figure 8. The shaded areas indicate regions with negative values.

enhancing the daytime sea breeze. This inflow is due to a small-scale relatively high-pressure area over Central Portugal which is generated during the afternoon pulling cold Atlantic air inland (Millán et al., 1991).

At 18 UTC the inflow from the north and from the south-east is strongest because the corresponding coastal pressure gradients are strongest. At the IP's eastern coast, a southerly flow parallel to the coast dominates in the morning whereas the inland flow increases until 18 UTC. The strong easterly surface flow between the Atlas mountains and the Iberian Cordillera system has been documented previously by Scorer (1952). He pointed out that a low-level isothermal layer is most common in this region during summer which enhances the easterly flow, frequently observed in the Strait of Gibraltar. At the southwestern coast of Spain, e.g. between Cadiz and Huelva, a strong sea breeze is encountered at 18 UTC which turns to a weaker land breeze around midnight (not shown).

The land and sea breezes play an important role in IP's coastal regions during summer because they occur on approximately 9 out of 10 days. The average speed reaches up to $3 \mathrm{~m} \mathrm{~s}^{-1}$ for the sea breeze which is active during the day, whereas the normally weak land breeze appears only for a few hours. An important aspect of the sea breeze is the extent to which it penetrates inland, which is on average about $50 \mathrm{~km}$. In summer, the inland penetration of sea breezes along the Mediterranean coast can reach over $100 \mathrm{~km}$, due to chanelling along valleys. Because the local surface flow is a combination of the mesoscale flow and the embedded sea breeze, one has to keep in mind that the latter is not sufficiently captured by the model due to its coarse resolution.

From the surface flow obtained for CL (Figure 5), it is possible to derive the thermal low's centre resulting from the inflow structures. The area within the IP where the minimum wind speed is of small-scale rotational character is assumed to be the approximate location of the Iberian thermal low's centre. Figure 6 shows the diurnal propagation of the wind-derived thermal low centre for CL (squares), indicating an apparent clockwise circulation. An explanation for this behaviour cannot be given here.

\subsection{Asymmetry of the Iberian thermal low}

A very apparent feature is the asymmetric character of the IP's thermal low which is obvious in the height of the 
(a)

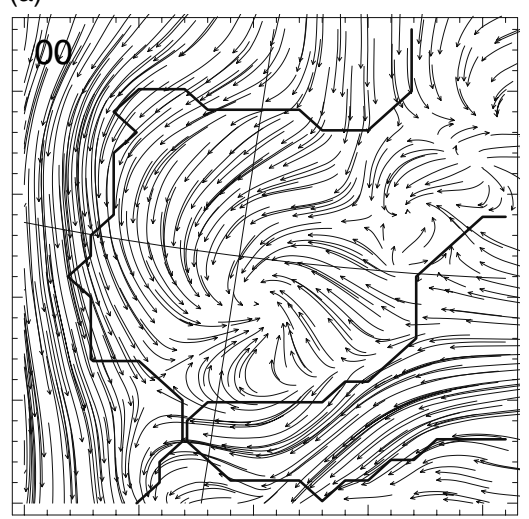

(c)

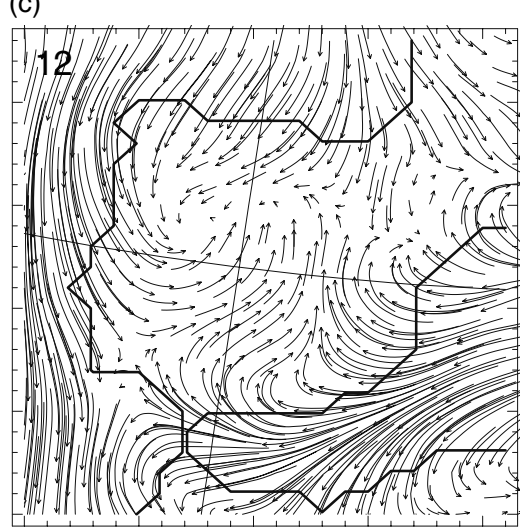

(b)

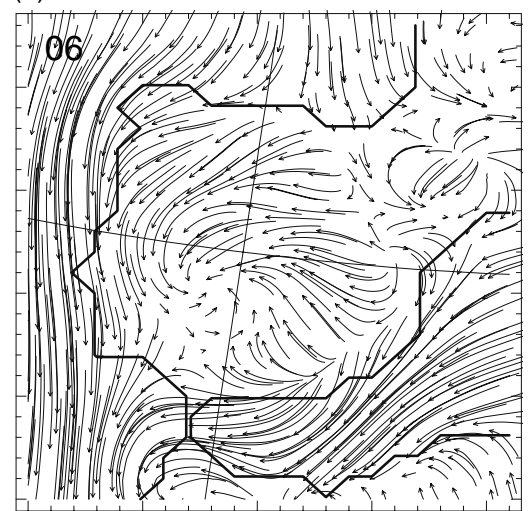

(d)

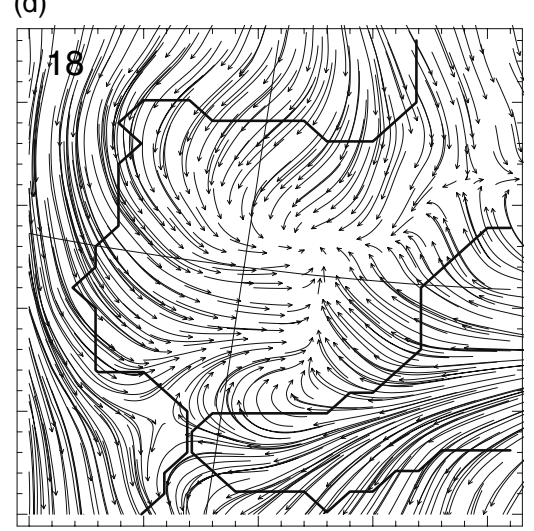

Figure 5. Diurnal evolution of 'streamlines' derived from surface winds for summer (JJA) thermal low days simulated for CL: (a) 00 UTC, (b) 06 UTC, (c) 12 UTC, and (d) 18 UTC.

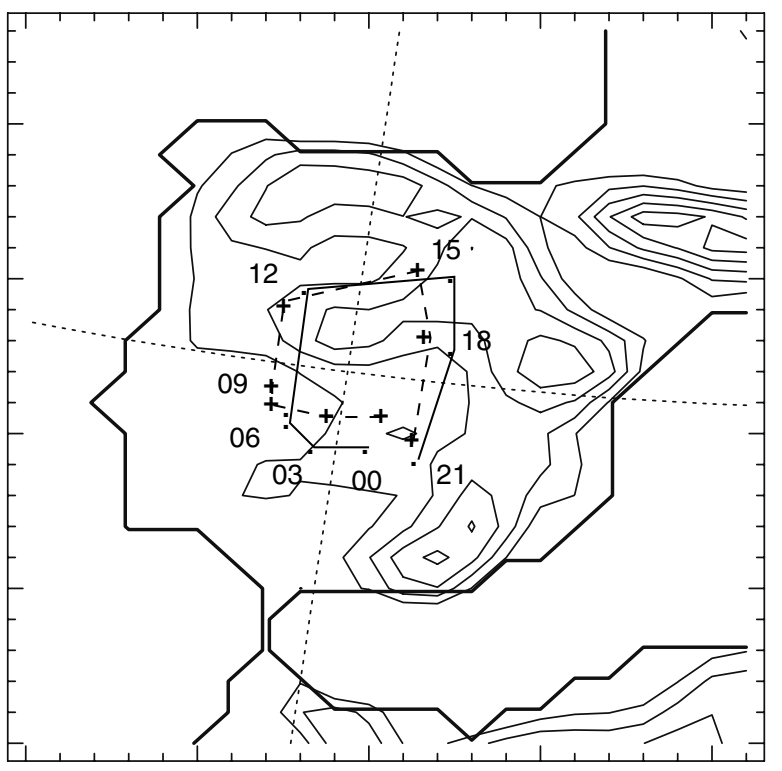

Figure 6. Diurnal evolution (summer, JJA) of the thermal low's centre, as derived from surface wind fields, with time given in UTC. The dots (cross) indicate the CL (A2) model realization. The fine contours indicate the corresponding PROMES orography starting at $500 \mathrm{~m}$ (with increment $500 \mathrm{~m}$ ).

$925 \mathrm{hPa}$ surface (Figure 3) and in the surface flow wind field (Figure 5), as well as in the surface vorticity and divergence, as shown by $\mathrm{HC} 03$. They indicated that, at the thermal low's peak hour (18 UTC), the divergence at $925 \mathrm{hPa}$ shows two convergence zones above the IP, one in the north-western part and another above the eastern part. During the entire day a maximum of anticyclonic vorticity was determined above south-eastern Spain and the Strait of Gibraltar. A maximum of cyclonic vorticity occurs between 18 and 00 UTC above the north-western IP. Note that cyclonic (anticyclonic) values are positive (negative) in the Northern Hemisphere.

Correspondingly, in the vertical the divergence structure evolves differently in the IP's zonal and meridional extremities. In the latitudinal cross-section the influence of the African continent with the Saharan thermal low forces an elevated minimum in divergence and vorticity above southern Spain, the latter reaching the upper troposphere (HC03). Zonal cross-sections show weak differences in divergence between the IP's Atlantic and Mediterranean sides. However the relative vorticity in the mid to upper troposphere shows cyclonic (anticyclonic) relative vorticity west (east) of the IP, related to the synoptic-scale location of the ridge. At low levels, a diurnal variation of the cyclonic vorticity maximum occurs between the southern and central regions of the IP.

Apparently, the asymmetry is due to the IP's complex topography and the non-homogeneous synoptic environment. The IP is surrounded by colder marine surfaces, except at its north-eastern edge, where the Pyrenees separate the peninsula from the European continent. The IP's 
complex topography shows barrier-like mountain ranges to the north, east and south, with two high plateaus in the centre divided by the system of central mountains. The high central plateaus gradually approach the coast in southern Portugal and south-western Spain as low-level plains.

The synoptic-scale atmospheric structure is characterized by a ridge of high pressure located over the eastern Atlantic Ocean. Above the IP which is located at the ridge's south-eastern edge, a north-easterly geostrophic flow prevails. This inhomogeneous synoptic environment leads to a variety of low-level pressure gradients at the Iberian coast (Figure 3): strong ones at its northern coast, weaker ones at its eastern and western coasts, and almost no gradient at its southern coast. The latter is due to the fact that the Iberian thermal low can sometimes be considered as a diurnal northerly extension of the African semi-permanent low. For the above-mentioned reasons, the resulting thermal low and its related circulation system are highly asymmetric in both zonal and meridional directions.

\section{Thermal lows in a changing climate}

In this section the summer averages, monthly frequency, daily evolution and surface flow of the Iberian thermal low in a changing climate are discussed by comparing simulations CL and A2.

\subsection{Iberian summer climate}

The contours on the summer $500 \mathrm{hPa}$ surface are shifted northwards by about $9^{\circ}$, which means that the surface is lifted by about $100 \mathrm{~m}$ (Figure 1(d)), as already reported elsewhere (Vidale et al., 2007). Accordingly the southern rim of the westerlies is shifted northwards and the IP's climate becomes more subtropical. The climate A2 modifications at the $500 \mathrm{hPa}$ geopotential surface (Figure 7(b)) indicate a ridge of high pressure of north-west/south-east orientation which is located above France. In contrast to this mid-tropospheric increase in pressure, the lower tropospheric field at $925 \mathrm{hPa}$ (Figure 7(a)) above the Iberian

(a)

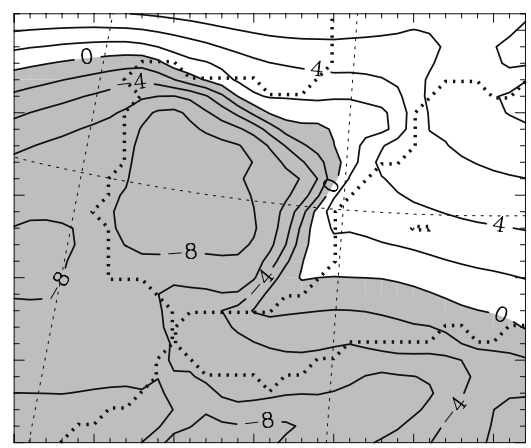

and Magreb regions is characterized by a decrease in height of up to $8 \mathrm{~m}$ and a related decrease in pressure. Off the western IP and the African continent there is a similar height decrease whereas east of the IP there is an increase in height. Thus at the IP's northern and eastern rim there are indications of a strengthening of the coastal gradients in this area in a changing climate.

The northward shift of the westerlies' southern rim as observed at $500 \mathrm{hPa}$ in the climatic scenario A2 results in a deepening of the mesoscale surface low above the IP at $925 \mathrm{hPa}$ (not shown), and additionally the Saharan thermal low extends further northward. This also leads to an increased latitudinal gradient in the geopotential height above northern Spain. The difference between A2 and CL (Figure 7(a)) clearly shows a deepening of more than $8 \mathrm{~m}$ above the IP as well as above the Magreb desert.

A reason for producing a pressure fall above land and a subsequent increase in the pressure gradient along its horizontal boundaries is the stronger summertime insolation, effective on the regional scale. Increased insolation and the subsequent stronger drying of the soil in a future climate enhances the strengthening of the thermal low, particularly over the central IP. This effect is included in the model simulations, as the atmospheric part is coupled to a land-surface model. Castro et al. (2005) determined that in a changing climate (CL to A2) there is an increase of summer daily mean surface temperature of 2-3 K north of the IP, 6-7 K above the IP and 3-4 K east of the IP.

\subsection{Monthly frequency}

The statistics of the entire series are given in Table I. The number of thermal low days increases significantly by more than $60 \%$. The annual evolution in the climate A2 appears to be the same as obtained for the control climate. Because the ERA-40 data are based on observations as well as modelling aspects, the annual variations are stronger than those obtained from RCM data only; this is indicated obviously by an approximate doubling of the standard deviation. In a changed climate, the seasonal frequencies are slightly increased (decreased) for

(b)

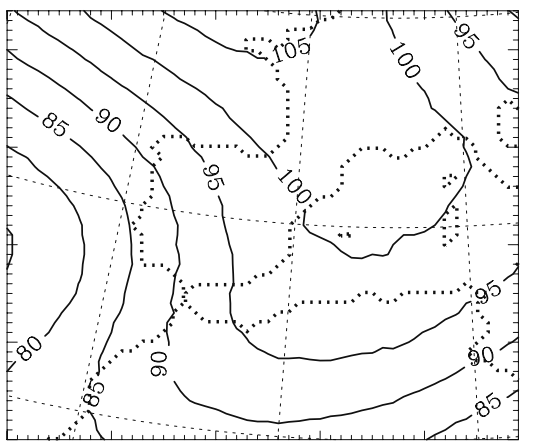

Figure 7. Summer average (JJA) of the difference climate simulation A2 minus control run CL: (a) $925 \mathrm{hPa}$ height (m) at 18 UTC, with increments of $2 \mathrm{~m}$; (b) $500 \mathrm{hPa}$ height (m) at $12 \mathrm{UTC}$, with increments of $5 \mathrm{~m}$. The shading denotes negative deviations, and the dotted lines indicate the coastline. 
autumn (summer), from $11 \%$ (76\%) to $15 \%$ (72\%). The springtime frequencies remain unchanged. Additionally, trends of the time series CL and A2 were determined. However, the resulting trend values have relatively small trend-to-noise ratios of less than 1.0. Thus the confidence levels were lower than $80 \%$.

\subsection{Daily evolution}

Figure 8 shows the daily evolution of the average summer height of the $925 \mathrm{hPa}$ surface for thermal low days as simulated for scenario A2. This figure should be compared with the corresponding CL patterns (Figure 3). The first four panels show the relaxation of the depression during the night. The minimum height of the thermal low becomes stronger at the peak time 18 UTC and the thermal low becomes more prominant between 21 and 00 UTC. During the night, the low relaxes again and the cycle starts anew. Correspondingly the central IP's mslp decreases from about $1012.2 \mathrm{hPa}$ (CL) to less than $1010.5 \mathrm{hPa}$ (A2). This decrease is statistically significant, according to the Aspin-Welsh test (Choi, 1978). The stronger depression leads to roughly $20 \%$ stronger gradients in geopotential height at the IP's northern and eastern rims. The gradients at the IP's western and southern boundaries remain unchanged.

The northern part of the Saharan depression, appearing in Figure 8, drops by $10 \mathrm{~m}$ at the $925 \mathrm{hPa}$ surface. Additionally, a weak signal of a thermal depression
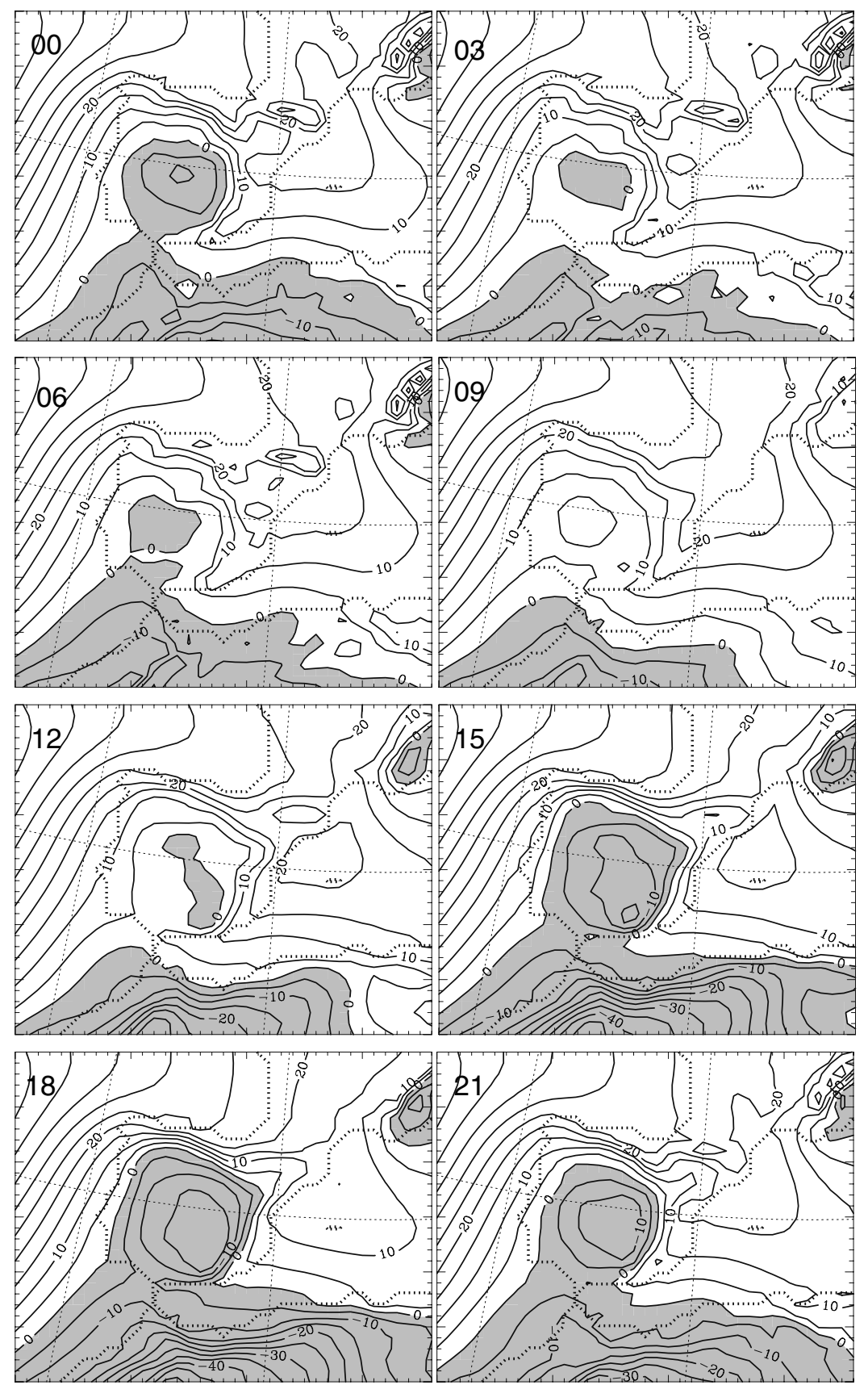

Figure 8. As Fig.3, but for climate A2. 
appears above the Alps, showing a peak signal around 15 UTC. This signal strengthens for A2. It should be mentioned here that the peak time of the daily evolution after the removal of the semi-diurnal pressure wave is also shifted towards $21 \mathrm{UTC}$, similar to CL (Figure 4; right column). A comparison between $\mathrm{CL}$ and A2 structure at 21 UTC shows also the strengthening of the isolated thermal low signal.

In a different approach, time series of ERA-40, CL and $\mathrm{A} 2$ data are used to determine the autocovariance function of the central IP's surface pressure. A brief introduction to the lagged-covariance technique is given in von Storch and Zwiers (1999). To get a temporal series of parameters characteristic for the IP's centre as well as for thermal lows, the criterion is applied where the differences in the $925 \mathrm{hPa}$ surface height between the inner and the peripheral region of the IP are determined (v). The averaged differences, obtained from various cross-coast differences form the considered time series. Figure 9 shows the autocovariances of the height difference averages as a function of time lag, $\tau$. There are significant positive autocovariances for the occurrence of central IP pressure distribution up to 2 days, although the autocovariances decrease with $\tau$. The summertime situation (EC-JJA) is characterized by a strong diurnal variation. For comparison, the winter condition is additionally shown for ERA-40 indicating a vanishing daily oscillation (EC-DJF). For CL and A2 comparably strong diurnal variations appear in summer. The only difference is apparent in the magnitude of the oscillation. The ERA-40 data show the weakest magnitude which increases for CL by about $7 \%$ and A2 by $14 \%$. Thus the increase between CL and A2 amounts to $7 \%$. This indicates the strengthening of the diurnal cycle in a changed climate.

A further statistic of interest is the length of period of consecutive thermal low days. Cubasch et al. (1996) predicted an increase in the probability of longer dry spells over southern Europe for all seasons, particularly in summer. Figure 10 depicts the length of periods for ERA40, CL and A2. The CL simulation shows that about $25 \%$ are one-day events whereas ERA-40 has less than $10 \%$. In a changing climate, the number of single-day events decreases to $15 \%$ of all thermal days and consequently there are many more events of more than 3 days. Thus in a changed climate the duration of thermal low periods becomes longer, with the result that insolation and drying probably become more effective. The difference between ERA-40 and CL is apparently larger than the climate change signal, at least for the frequency of short thermal low periods due to the difference between the observed climate and the control model climate, as discussed in Section 3.2.

\subsection{Surface flow}

In general, the surface flow structure in A2 is similar to $\mathrm{CL}$, but slightly stronger in magnitude as depicted in Figure 11. We find an increase in wind speed by

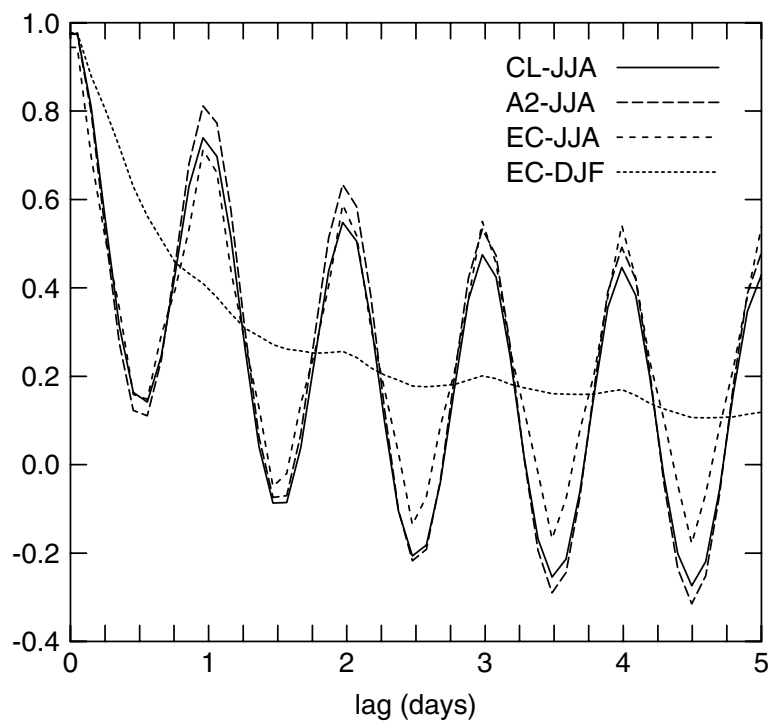

Figure 9. Autocovariance of averaged $925 \mathrm{hPa}$ height differences between inner and peripheral IP, as a function of time-lag, $\tau$ : winter ERA-40 (EC-DJF), and summer ERA-40 (EC-JJA), CL (CL-JJA), and A2 (A2-JJA).

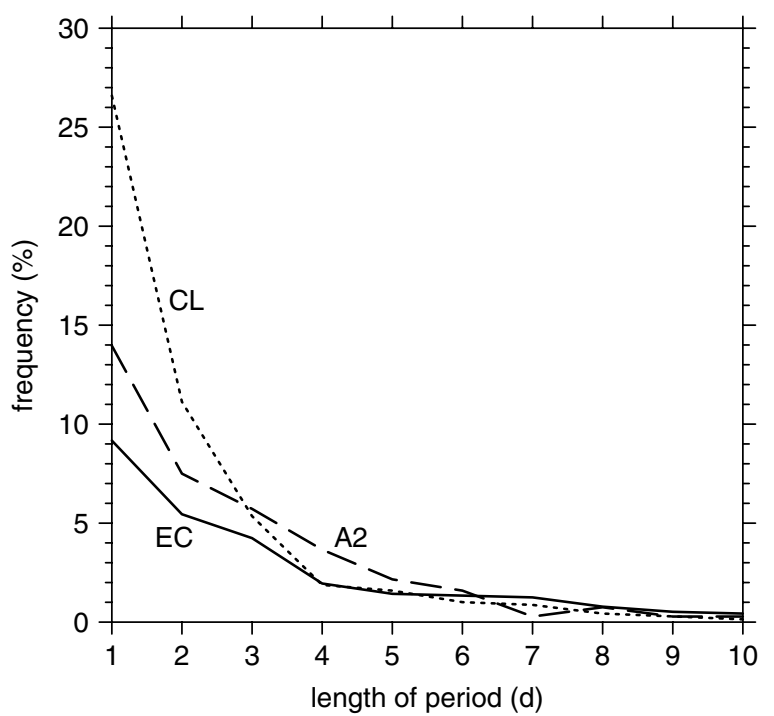

Figure 10. Frequencies of the length (in days) of the summer (JJA) thermal low periods for the IP, obtained from ERA-40 (EC) and RCM (CL and A2).

10-20\% particularly for the IP's north-western and south-central part. There is a cyclonic curved flow at the north-western edge of the IP indicating an increase of the coast-parallel flow. The flow toward the Portuguese coast increases, indicating an enhancement of the daytime sea breeze, particularly in southern Portugal and south-western Spain. The easterly flow toward Gibraltar analysed for the present climate (Figure 5) is reduced in a changed climate. At the IP's eastern coast, the landward cross-coastal flow shows mariginal increases. The main difference between 00 and 12 UTC is that in the IP's centre we find an increased north-easterly (southwesterly) flow in northern (southern) Spain during the night. 
(a)

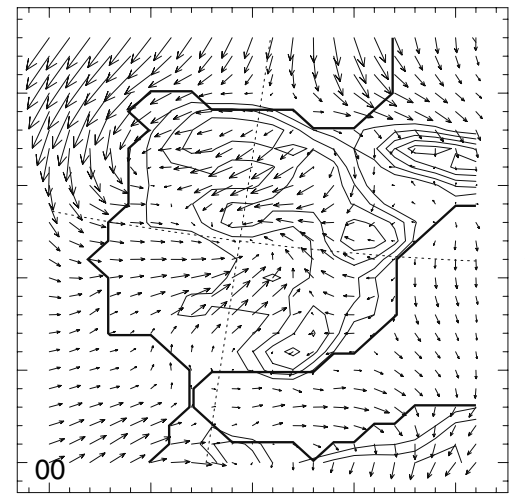

(b)

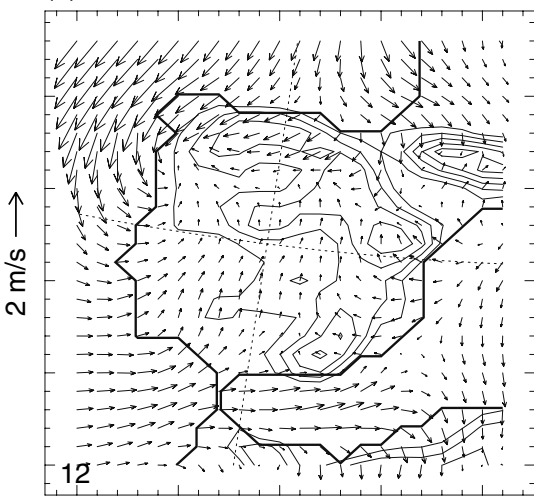

Figure 11. Differences in the surface wind (A2 minus CL) for (a) 00 and (b) 12 UTC. The fine contours indicate the corresponding PROMES orography starting at $500 \mathrm{~m}$ (with increment $500 \mathrm{~m}$ ).

From the surface flow graphs obtained for A2 (not shown), it is possible to derive the thermal low's centre resulting from the inflow structures for A2, similar to CL (see Section 3.3). Figure 6 exhibits the diurnal propagation of the wind-derived thermal low centre for A2 (crosses). The differences between CL and A2 are minor. However, the clockwise rotation in A2 is shifted slightly to the west. The small differences of the wind-derived thermal low centre between $\mathrm{CL}$ and A2 are consistent with the corresponding $925 \mathrm{hPa}$ surface differences (not shown), as the largest reduction in height in A2 compared to $\mathrm{CL}$ at this level occurs over the western IP.

\section{Concluding remarks}

In this study, climatological features of the Iberian thermal low are determined for today's climate by using ERA-40 data and data provided by the regional climate model PROMES. Two series of simulations with the regional climate model, nested in an atmospheric global climate model (HadAM3), are considered in order to get thermal low statistics for the present climate, a control run $\mathrm{CL}$, and a changed climate scenario A2. One has to keep in mind that the results strongly depend on the GCM within which the regional climate model is nested (Räisänen et al., 2004). In the following, the main results are summarized for today's Iberian thermal lows and for those in a changed climate.

The RCM simulation exhibits conditions which, however, are not as favourable for thermal lows as those provided by the ERA- 40 data. Only $41 \%$ of the thermal low days of ERA-40 are seen in the model's control state CL. This result is likely related to the criteria used for selected heat low days. Nevertheless, in general the atmospheric structures analyzed by ERA-40 and simulated by the RCM are comparable.

The comparison of the CL with the A2 state shows an increase in number of thermal low days by more than $60 \%$. In turn, there exists an increasing number of longer periods of consecutive thermal low days (3-6 days).
There is also a lowering of the central pressure from $1012.2 \mathrm{hPa}$ to $1010.5 \mathrm{hPa}$ which leads to an increase of $7 \%$ in the daily amplitude of the central Iberian mslp. This is associated with a strengthening by more than $20 \%$ of the surface pressure gradients along the Iberian coasts. Above the north-western IP there is an increase in cyclonic curved surface flow. The sea breezes are enhanced above the IP's Atlantic and Mediterranean coasts, in particular there is a significant strengthening of the sea breeze between Cadiz and Huelva. Additionally, the easterly flow through the Strait of Gibraltar weakens.

All this indicates that the subtropical character of the Mediterranean climate is strengthened, at least in its southernmost region. The IP is one of the driest Mediterranean regions. As land degradation occurs, soil storage capacity is reduced, run-off increases and erosion thresholds are passed. Corte-Real et al. (1998) determined that over the last three decades, springs in Portugal are becoming drier, the rainy season is ending earlier and the onset of the dry season is occurring earlier. Large parts of south-eastern Spain are areas vulnerable to desertification (e.g. Goodess et al., 1998). High interannual variability in precipitation and high summer temperatures lead to a more or less continuous threat of water scarcity. The heavy reliance on irrigation for agriculture production in Mediterranean countries is obvious because in Spain (Portugal) around 70 (50)\% of water is used for irrigation. A further major environmental concern in the Mediterranean area is the occurrence of devastating summer forest wildfires. The analysis of fire records suggested a clear increase in the annual number of fires and areas burned during the last century; however, in the last three decades the number of fires also increased but the area burned did not show a similar clear trend.

Additionally, our results indicate an intensification of the Saharan thermal low which might have an indirect effect on the IP's climate. Intensified insolation in the Sahara Desert creates strong surface winds and convection, which lifts dust particles to an elevation of approximately $6 \mathrm{~km}$ (Quereda et al., 1996). Under favourable conditions $(\approx 5 \%$ annually $)$ the dust plumes are tranported by the prevailing winds to western Europe. The 
increase of dust in the atmosphere affects the weather by altering the radiative budget which may change the mid-tropospheric atmospheric stability and modify cloud nucleation processes.

Therefore, the forecasted increase in temperature and decrease of precipitation in a changed climate which in turn results in an increased number and temporal extension of thermal low events will affect the IP in various socio-economic sensitive areas. The issue of desertification, being already critical, will increase in importance as our results indicate. In a changed climate the irrigation-based agricultural production will become more problematic and the number of summertime dry spells will increase as well. Based on calculated firerisk indices, Carvalho et al. (2001) pointed to a potential serious increase of forest fire occurrences in Portugal in a climate change scenario. Similar conditions have been predicted in many other ecosystems, e.g. Australia (Williams et al., 2001).

The analyses presented here and in $\mathrm{HC} 03$ show strong asymmetries in the dynamic and thermodynamic thermal low structure above the IP. These complex asymmetries are normally not considered in idealized numerical simulations published elsewhere. Obviously, there is a gap between the observed thermally forced circulation in a thermal low above a certain topography and that simulated by simplified idealized models. The latter approach usually assumes a quiescent environment which allows the development of an undisturbed divergent anticyclone aloft. Further idealizations are simplified orography. Clearly, idealized models are a powerful tool to study basic processes; however, simulations of realistic 3D circulations above a selected topographic region are more diffcult to perform within the framework of an idealized model. At present, adequate studies simulating realistic 3D thermal lows above complex terrain are rare, at least for Iberia.

\section{Appendix}

For convenience, the criteria are given which are applied to determine Iberian thermal lows. For more details see $\mathrm{HC} 03$.

(i) At 06 and 18 UTC, the mslp above the IP (Figure A1; area A) must be larger than $1002 \mathrm{hPa}$, allowing one grid point exception.

(ii) At 06 UTC, the grid-point-averaged mslp must be greater than $1011 \mathrm{hPa}$ at the northern and northwestern rim of the IP (Figure A-1; squares in region $\mathrm{NW}$ and $\mathrm{N}$ ).

(iii) At $18 \mathrm{UTC}$, the minimum height of the $925 \mathrm{hPa}$ surface must be located above the IP's centre (area bounded by $7.5^{\circ} \mathrm{W}, 1.5^{\circ} \mathrm{W}, 38.0^{\circ} \mathrm{N}$ and $42.5^{\circ} \mathrm{N}$ ) considering all grid-point data from area $\mathrm{A}$ of Figure A-1.

(iv) The grid-point-averaged mslp tendency between 06 and 18 UTC must be negative in the south-eastern corner of the IP (Figure A-1; triangles in region SE).

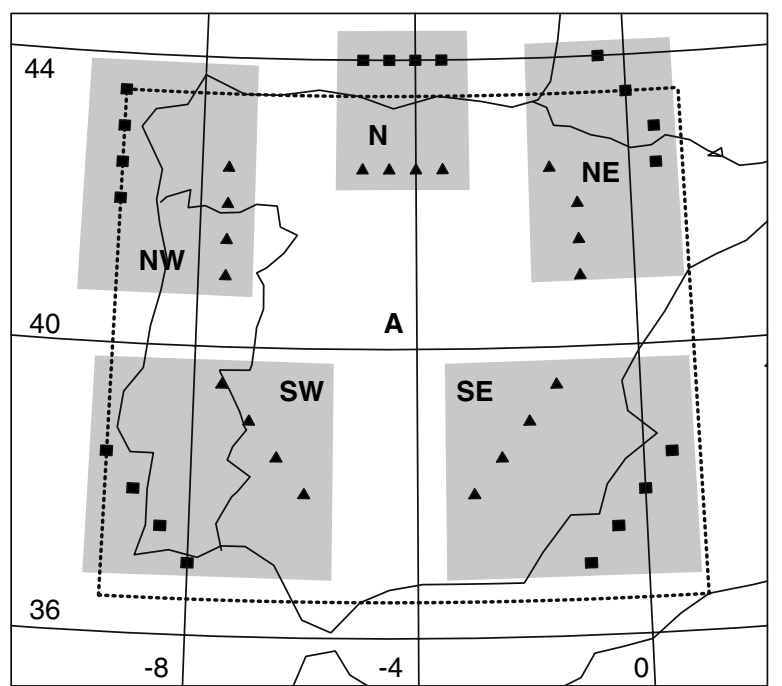

Figure A1. Scheme of criteria to determine thermal low days. Criteria (i) and (iii) are applied within region A limited by the dotted line. The shaded areas (NW, etc.) indicate the regions where differences in the averaged grid point values between the interior (triangles) and peripheral (squares) areas are calculated for criterion (v) (taken from Hoinka and Castro, 2003).

(v) At 18 UTC, the grid-point-averaged height of the $925 \mathrm{hPa}$ surface above the interior area (triangles) must be less than or equal to that of the peripheral area (squares) within all considered regions separately (NW, $\mathrm{N}$, etc.).

\section{Acknowledgements}

George Craig (DLR) is thanked for smoothing the English language of the text.

\section{References}

Anthes RA, Hsie E-Y, Kuo Y-H. 1987. 'Description of the PENN State/NCAR Mesoscale Model Version 4 (MM4)'. Technical Note 282. NCAR: Boulder, USA.

Castro M, Fernandéz C, Gaertner MA. 1993. Description of a mesoscale atmospheric numerical model. Pp 230-253 in Mathematics, climate and environment. Diaz JL, Lions JL. (eds.) Res. Notes Appl. Math. 27: Masson, Paris, France.

Castro M, Martin-Vide J, Alonso S. 2005. The climate of Spain: Past, present and scenarios for the 21st century. Pp 1-62 in A preliminary assessment of the impacts in Spain due to the effects of climatic change. Moreno JM. (ed.) Ministry of Environment of Spain. Available at: http://www.mma.es/secciones/cambio_climatico/.

Carvalho AC, Carvalho A, Miranda AI, Borrego C, Rocha A. 2001. Climate change and fire weather risk. Pp 555-565 in Detecting and modelling regional climate change. Brunet M, López D. (eds.) Springer: Berlin, Germany.

Choi SC. 1978. Introductory Applied Statistics in Science. Prentice-Hall Inc: Englewood Cliffs, New Jersey, USA.

Christensen JHT, Carter T, Giorgi F. 2002. PRUDENCE employs new methods to assess European climate change. EOS 83: 147.

Corte-Real J, Sorani R, Conte M. 1998. Climate change. Pp 34-36 in Atlas of Mediterranean Environments in Europe. Mairota P, Thornes JB, Geeson N. (eds.) John Wiley \& Sons: Chichester, UK.

Cubasch U, von Storch H, Waszkewitz J, Zorita E. 1996. Estimates of climate change in southern Europe from dynamical climate model output. Clim. Res. 7: 129-149.

Dai A, Wang J. 1999. Diurnal and semidiurnal tides in global surface pressure fields. J. Atmos. Sci. 56: 3874-3891.

van den Dool HM, Saha S, Schremm J, Huang J. 1997. A temporal interpolation method to obtain hourly atmospheric surface pressure tides in reanalysis 1979-1995. J. Geophys. Res. 102: 22 013-22 024. 
Ducoudré N, Kaval K, Perrier A. 1993. SECHIBA, a new set of parameterizations of the hydrologic exchanges at the land-atmosphere interface within the LMD atmospheric general circulation model. J. Climate 6: 248-273.

Fronzek S, Carter TR. 2007. Assesing uncertainties in climate change impacts on resource potential for Europe based on precipitations from RCMs and GCMs. Clim. Change in press.

Gadd AJ. 1978. A split-explicit integration scheme for numerical weather prediction. Q. J. R. Meteorol. Soc. 104: 569-582.

Gaertner MA, Christensen OB, Prego JA, Polcher J, Gallardo C, Castro M. 2001. The impact of deforestation on the hydrological cycle in the Western Mediterranean: An ensemble study with two regional climate models. Clim. Dyn. 17: 857-873.

Gibson R, Kållberg P, Uppala S, Hernandez A, Nomura A, Serrano E. 1997. 'ERA description'. Re-analysis Project Report No.1. ECMWF: Reading, UK.

Goodess CM, Mariani L, Palutikof JP, Menichini V, Minardi GP. 1998. Estimating future climates in the Mediterranean. Pp 38-42 in Atlas of Mediterranean Environments in Europe. Mairota P, Thornes JB, Geeson N. (eds.) John Wiley \& Sons: Chichester, UK.

Haurwitz B. 1956. The geographical distribution of the solar semidiurnal pressure oscillation. New York Univ. Coll. Eng. Meteorol. Paper 2(5): 1-36.

Hoinka KP. 2007. Semi-diurnal pressure fluctuations in the ERA-40 data. Meteorol. Zeitschrift in press.

Hoinka KP, Castro M. 2003. The Iberian Peninsula thermal low. $Q$. J. R. Meteorol. Soc. 129: 1491-1511; (Corrigendum 2006, Q. J. R. Meteorol. Soc. 132: 1377).

Hsu H, Hoskins BJ. 1989. Tidal fluctuations as seen in ECMWF data. Q. J. R. Meteorol. Soc. 115: 247-264.

IPCC 2000. IPCC special report on emission scenarios. Nakicenovic N, Swart R. (eds.) Cambridge Univ. Press: Cambridge, UK.

IPCC 2001. Climate change 2001: The scientific basis. Contribution of Working Group I to the Third Assesment Report of the Intergovernmental Panel on Climate. Houghton JT, Ding Y, Griggs DJ, Noguer M, van der Linden PJ, Dai X, Maskell K, Johnson CA. (eds.) Cambridge University Press: Cambridge, UK and New York, USA.

Jacob D, Bärring L, Christensen OB, Christensen JH, de Castro M, Déqué M, Giorgi F, Hageman S, Hirschi M, Jones R, Kjellström E, Lenderink G, Rockel B, Sánchez E, Schär C, Seneviratne SI, Somot S, van Ulden A, van der Hunk B. 2007. An intercomparison of regional climate models for Europe: Model performance in presentday climate. Climatic Change in press. DOI: 10.1007/s10584-0069218-Z.
Linés, A. 1970. The climates of the Iberian Peninsula. Pp 195-239 in Climates of Northern and Western Europe. Wallén CC. (ed.) World Survey of Climatology 5. Elsevier: Amsterdam, The Netherlands.

Millán M, Artiñano B, Alonso S, Navazo M, Castro M. 1991. The effect of mesoscale lows on regional and long-range atmospheric transport in the western Mediterranean area. Atmos. Environ. 25A: 949-963.

Mohr M. 2004. Problems with the mean sea level pressure field over the western United States. Mon. Weather Rev. 132: 1952-1965.

Portela A, Castro M. 1991. Primera aproximación a una climatologíia de las depresiones térmicas en la Península Ibérica. Rev. de Geofísica 47: $205-215$.

Quereda J, Olcina J, Montón E. 1996. Red dust rain within the Spanish Mediterranean area. Clim. Change 32: 215-228.

Räisänen J, Hansson U, Ullerstig A, Döscher R, Graham LP, Jones C, Meier HEM, Samuelsson P, Willén U. 2004. European climate in the late twenty-first century: Regional simulations with two driving global models and two forcing scenarios. Clim. Dyn. 22: 13-31.

Schönwiese C-D, Rapp J, Fuchs T, Denhard M. 1994. Observed climate trends in Europe 1891-1990. Meteorol. Zeitschrift (NF) 3: 22-28.

Scorer RS. 1952. Mountain-gap winds: A study of surface winds at Gibraltar. Q. J. R. Meteorol. Soc. 78: 52-61.

Uppala SM, Kallberg PW, Simmons AJ, Andrae U, da Costa Bechtold V, Fiorino M, Gibson JK, Haseler J, Hernandez A, Kelly GA, Li X, Onogi K, Saarinen S, Sokka N, Allan RP, Andersson E, Arpe K, Balmaseda MA, Beljaars ACM, van de Berg L, Bidlot J, Bormann N, Caires S, Chevallier F, Dethof A, Dragosavac M, Fisher M, Fuentes M, Hagemann S, Hólm E, Hoskins BJ, Isaksen L, Janssen PAEM, Jenne R, McNally AP, Mahfouf J-F, Morcrette J-J, Rayner NA, Saunders RW, Simon P, Sterl A, Trenberth KE, Untch A, Vasiljevic D, Viterbo P, Woollen J. 2006. The ERA-40 re-analysis. Q. J. $R$ Meteorol. Soc. 131: 2961-3012.

Vidale PL, Lüthi D, Wegmann R, Schär C. 2007. European climate variability in a heterogeneous multi-model ensemble. Clim. Change in press.

von Storch H, Zwiers FW. 1999. Statistical analysis in climate research. Cambridge University Press: Cambridge, UK.

Williams AAJ, Karoly DJ, Tapper N. 2001. The sensitivity of Australian fire danger to climate change. Clim. Change 49: 171-191.

Zhang DL, Anthes RA. 1982. A high-resolution model of the planetary boundary layer - sensitivity test and comparisons with SESAME-79 data. J. Appl. Meteorol. 21: 1594-1629. 